\title{
INTERNAL CONVERSION COEFFICIENTS IN THE DECAY OF ${ }^{91} \mathrm{Kr}$
}

\author{
Robert Stephen Weinbeck
}

Ph. D. Thesis Submitted to Iowa State University

Ames Laboratory, ERDA

Iowa State University

Ames, Iowa 50010

Manuscript Date: November, 1974

This report was prepared as an account of work
sponsored by the United States Government. Neither
the United States nor the United States Energy
Research and Development Administration, nor any of
their employees, nor any of their contractors,
subcontractors, or their employees, makes any
warranty, express or implied, or assumes any legal
liability or responsibility for the accuracy, completeness
or usefulness of any information, apparatus, product or
process disclosed, or represents that its use would not
infringe privately owned rights.

PREPARED FOR THE U.S. ENERGY RESEARCH AND DEVELOPMENT ADMINISTRATION

DIVISION OF RESEARCH UNDER CONTRACT NO. W-7405-eng-82 


\section{DISCLAIMER}

This report was prepared as an account of work sponsored by an agency of the United States Government. Neither the United States Government nor any agency Thereof, nor any of their employees, makes any warranty, express or implied, or assumes any legal liability or responsibility for the accuracy, completeness, or usefulness of any information, apparatus, product, or process disclosed, or represents that its use would not infringe privately owned rights. Reference herein to any specific commercial product, process, or service by trade name, trademark, manufacturer, or otherwise does not necessarily constitute or imply its endorsement, recommendation, or favoring by the United States Government or any agency thereof. The views and opinions of authors expressed herein do not necessarily state or reflect those of the United States Government or any agency thereof. 


\section{DISCLAIMER}

Portions of this document may be illegible in electronic image products. Images are produced from the best available original document. 
This report was prepared as an account of work sponsored by the United States Government. Neither the United States nor the United States Energy Research and Development Administration, nor any of their employees, nor any of their contractors, subcontractors, or their employees, makes any warranty, express or implied, or assumes any legal liability or responsibility for the accuracy, completeness, or usefulness of any information, apparatus, product or process disclosed, or represents that its use would not infringe privately owned rights.

Available from: National Terhnical Information Service U. S. Department of Commerce P.O. Box 1553

Springfield, VA 22161

Price: Microfiche $\$ 2.25$ 
Internal conversion coefficients

in the decay of $91 \mathrm{Kr}$

by

Robert Stephen Weinbeck

A Thesis submitted to the

Graduate Faculty in Partial Fulfillment of

The Reguirements for the Degree of

MASTER OF SCIENCE

Department: Physics

Major: Nuclear Physics

Approved :

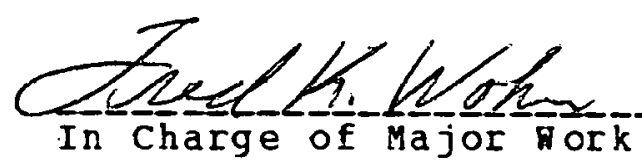

Por the Major De partment

For the Graduate college

Iowa State University

Am es, Iowa

1974 
TABLE OF CONTENTS

Page

I. INTECIUCT ION

II. REVIEW OF LITERATURE

III. EXPEEIMENTAL FACILITY 7

A. TRISTAN Isotópe SEparator system 7

B. Beta-ray spectrometer System 10

1. Spectrometer desiqn 10

2. Field control system 13

3. Data collection system 16

4. Beam collecticn system 23

IV. METEOD OF ANALYSIS 27

$\begin{array}{ll}\text { A. Introduction } & 27\end{array}$

B. Scurce Preparation 31

C. Measurements and Analysis 33

V. SUMMARY AND CONCLUSIONS 47

VI. ITTEBATURE CITED

VII. ACKNOWLEDGMENS 
Page

Fiqure 1. Physical layout of the TRISTAN isotope separator facility

Fiqure 2. Cross-section of the TRISTAN beta-ray spect rometer

Fiqure 3. Simpiified top view of the TrISTAN beta-ray spectrometer

Fiqure 4. Elock diaqram of maqnetic field control system

Fiqure 5. Data collection system

Fiqure 6. Cross-section of the dual detector

Hiqure 7. Plot of chandel numbers for various inverse-square current settings

Fiqure 8. Mass 91 isotopes and levels in this study

Fiqure 9. Iriternal conversion lines of $93.6-k e v$ and $108.8-\mathrm{keV}$ transitions

Fiqure 10. Livetime-corrected Ge(Li) detector count rate

Fiqure 11. 93.6-keV K-conversion line from third source 
Page

Table 1. Plexiglas attenuation coefficients

Table 2. Results of conversion coefficients in the decay of $91 \mathrm{Kr}$

Table 3. Internal conversion coefficients and ratios 
Internal conversion coefficients

in the decay of $91 \mathrm{Kr}^{1}$

Robert st ephen Weinbeck

Under the supervision of

F. K. Woh n

From the Department of Physics

Iowa state University

The use of a Bartlett-type $\pi \sqrt{2}$ double-focusing beta-ray spectrometer on-line to the TRISTAN isotope separator at ames Laboratory for measurements of internal conversion coefficients is described. The K-conversion coefficient of the 108.8-kev transition to the ground state in the $91 \mathrm{KI}$ decay was deduced to be $0.109 \pm 0.007$. The $K$-conversion coefficient of the $93.6-k e v$ transition to the ground state in the $91 \mathrm{Rb}$ decay was determined to be 1.10 \pm 0.09 . The 93.6-kev $\mathrm{K} / \mathrm{L}$ ratio was deduced to be $5.95 \pm 0.24$. These results are related to earlier studies, and conclusions in terms of the she11 model are given.

1 USAEC REPOIt IS-T-654. This work was performed under contract $\$-7405-e n g-82$ with the U.S. Atomic Energy Commission. 
viii

Distribution:

1

Oak Ridge, Tennessee

1

Ames Laboratory 


\section{INTRODUCTION}

Current research in nuclear physics is directed at determining the nature of the strong interaction. This is accomplished by the gathering of all experimental data possible and applying it to evaluate theoretically developed models which have been proposed. A's the models become more sophisticated and experimental information becomes more precise and abundant, it is hoped that the emerging picture will approach a closer understanding of the nature of the nuclear force.

Some of the observables which can be used to test proposed theories are the energies of excited nuclear levels, as well as the transitions between these levels, the spins and parities of these nuclear states, ard nuclear moments. Excited state energies are easily obtained but are less discriminating between various models. A more definitive test to discriminate between various models is in the use of angular momenta, or spins, and the parities of the states. unfortunately, the spins and parities of excited levels can only be deduced by determining the multipolarities of transitions between states. Then, by the use of all available decay information, including the energies and intonsities of all decay processes lalpha, beta, and gama emission, as well as internal conversion: processes, which populate and depopulate each level), an energy level scheme can be estab- 
lished, and possible spin and parity assignments can be made indirectly. A trivial example might be the formation of a nuclide in an excited state following the beta decay of the parent, an even-even nucleus. Only one gamma ray is observed in the decay, and the internal conversion electron spectrum, to be mentioned later, definitely characterizes the transition. The gamma ray would determine the energy of the excited level. The nature of the beta-decay spectrum could be used to help determine the spin and parity of the excited level, and the internal conversion spectrum is useful to help determine the spin and parity of the ground state. The level scheme. can then be compared to the predictions of a nuclear model, such as the shell model.

one very sensitive method of determining multipolarities of nuclear transitions is by measurement of the Internal conversion çofficient (ICC) associated with the transition. An excited nucleus, rather than decaying by emission of a gamma ray, may transfer the excess energy to one of its orbital electrons which is then ejected. The ICC of a nuclear transition is defined to be the number of electrons ejected from a particular atomic orbit per quantum emitted (1). The ICC depends on the particular atomic electrons involved, the transition energy and, most importantly, the multipolarity of the radiative transition. Since the wave functions of the atomic orbits are well-known and the nature of the electro- 
magnetic interaction is believed to be well-understood, a measurement of the ICC can be a very accurate way to determine the multipolarity. Extensive tables of ICCs are now tabulated (2). 


\section{II . REVIEW OF LITERATURE}

This study was undertaken to resolve certain inconsistencies which have appeared in the literature concerning the decays of $91 \mathrm{Kr}$ and its daughter, $91 \mathrm{Rb}$. The 1ow-1ying, first excited levels in $92 \mathrm{Rb}$ and $91 \mathrm{Sr}$ have been deduced to have conflicting parity assignments in the different studies mentioned below.

Mason and Johns (3) investigated the decay of $91 \mathrm{Rb}$. They deduced a total ICC for the transition from the firstExcited state of $91 \mathrm{Sr}$ at $93.6 \mathrm{keV}$, by comparing the intensities of all the gamma rays okserved to populate this level, minus those depopulating it, and assuming no excited-state fesding by beta decay. This ICC deduced for the 93.6-kev level provided an lower limit to the actual ICc. The limit of $0.9 \pm 0.2$ implied that the transition was primarily E2, since a pure E2 transition has a total ICC of 1.3 for this nucleus and energy (2).

Malmskog and MaCDonald (4) also investigated the $91 \mathrm{Rb}$ decay.. They measured the $K /(L+M+\ldots)$ ratio and deduced a total ICC for the $93.6-k e v$ transition. The $K /(L+M+\ldots)$ ratio was $5.38 \pm 0.21$ compared with ratios of $4.96,7.17$, and 5.62 for E2, M1, and M2 transitions, respectively. 'l'hey ruled out the M2 possibility on level lifetime measurements. This ratio then implied a transition which was ( $81 \pm 9) \% \mathrm{E} 2$, and 
had a total: ICC of 1.1, in good agreement with the estimate of Mason and Jchns.

During the investigation of a series of decays, Halbig (5) obtained prelimidary data on the decays of $91 K 5$ and $91 \mathrm{Rb}$. In the decay of $91 \mathrm{Kr}$, he mea sured the $\mathrm{K}$-conversion coefficient for the 108.8-keV transition. The result, $0.412 \pm$ 0.024 . was consistent with an M1/E2 transition. In the decay of $91 \mathrm{Rb}$, however, the K-conversion coefficient was $4.16 \pm$ 0.46, consistent with $12 /$ E3 mixing: The measured K/L ratio Has $6.42 \pm 0.58$. This could have been either E2 or M2. The attempt to verify these results by repeating the mea surements $1 \in d$ to different answers, although the ratio of the $93.6-\mathrm{keV}$ to $108.8-k e V k-c o n v e r s i o n$ coefficients was very reproducible. This lack of reproducibility led to a lack of confidence in the calculated ICC values and a need to repeat the measurements. If the 93.6-kev transition were, in fact, in the M2/E3 range, It would imply that the transition is paritychanging. Since the ground state of $91 \mathrm{Sr}$ is well-established to be $5 / 2+(6)$, as predicted by the shell model, all lowIying, excited states should consist of configurations of the three $d_{5 / 2}$ neutrons. Therefore, no opposite parity level should be seen at such a low energy.

Becently. Achterburg et_al reverse situation from the conclusions of Halbig. By taking simultaneous beta-gamma 'singles measurements with a Si(Li) - 
Ge(Li) detector combination, they have found the 108.8-kov Kconversion coefficient to be $0.067 \pm 0.012$ and the 93.6-kev $k$-conversion coefficient to be $1.05 \pm 0.10$. This implies that the 108.8-keV transition is E1, i.e. parity-changing, while the 93.6-keV transition is E2. This would place the parity-charging transition in $91 \mathrm{Rb}$ rather than $91 \mathrm{Sr}$, which is just as perplexing for the shell model to explain. The shell model predicts a ground state of $5 / 2$ - corresponding to a proton hole in the $\mathbf{f}_{5 / 2}$ shell. All other low-lying states should consist of $\mathrm{f}_{5 / 2}$ or $\mathrm{p}_{3 / 2}$ hole mixtures, all negative parity.

It was therefore felt that new measurements of these ICcs should be attempted to determine which value is the correct one. If a parity-changing transition between the lowest excited-level and the ground state exists in either $92 \mathrm{Rb}$ or $91 \mathrm{SI}$, it would present a serious departure from the well-established shell model explanations of low-lying excitations in this region of nuclei. 


\section{EXPERIMENTAL FACILITY}

\section{A. TRISTAN Isotope separator System}

The ICC measurements reported in this study were made using the TRISTAN isotope separator on-line to the Ames Laboratory, Research Reactor $(8,9)$. The layout of the TRISTAN system is shown in figure 1. The reactor is a heavy water moderated and cooled type, using enriched $235 \mathrm{U}$ fuel, and operates at a thermal power of five megawatts. A fission product generator, which is an aluminum can containing approximately ten grams of uranium stearate powder on trays within the can, is located in a neutron beam emerging from the reactor. The thermal neutron flux at that point is approximately $3 \times 10^{9}$ thermal neutrons per $c m^{2}$ per second.

Emanation of fission products from the generator is significant only for the rare gases. KI and Xe. Other products are held up in the stearate or transport line and do not reach the ion source. To assist the transport through the 1.7-m transfort line, a sweep gas of $98 \% \mathrm{He}, 1 \% \mathrm{Kr}$, and $1 \% \mathrm{Xe}$ is added. This sweep gas also aids in the later identification of beam components and in focusing of a sharp beam profile.

After passing through the transport line, the sweep gas and contaminants are ionized in the ion source. The resulting ions are accelerated through a potential of 50 to $60 \mathrm{kV}$ 


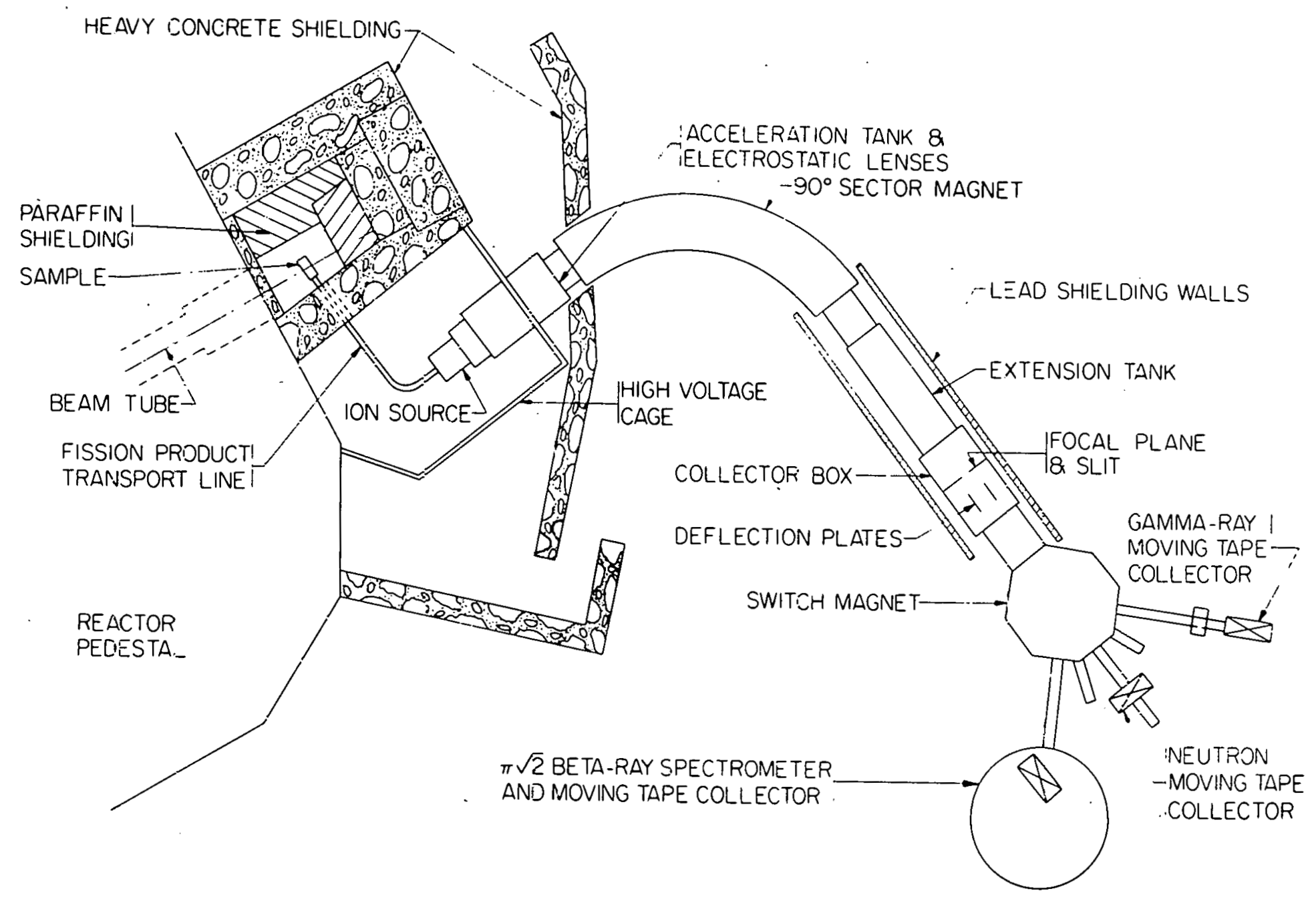

Fiqure 1. Physical layout of the TRISTan isotope separator facility 
before introduction into the $1.6-m$ radius, $90^{\circ}$ sector magnet where mass separation occurs. Since the vast majority of the ions are $K r$ and $X e$, mass separation is effectively isotopic separation of either the $\mathrm{Kr}$ or $\mathrm{xe}$ isotopes. The sector magnet provides a dispersion between adjacent masses of about $1.8 \mathrm{~cm}$ for the $A=90$ region at the focal plane in the collector box. There are also two electrostatic lens for focusing of the isobaric beams. The optimum beam profile, as seen in the collector box, is a line about $1 \mathrm{~mm}$ wide by $2 \mathrm{~cm}$ high.

By adjusting the separator magnet current, the beam of interest is directed to a slct between two plates in the ccllector box. The plates stop all other mass-separated beans within $\pm 8 \%$ of the central mass and allow the desired beam to reach the experimental apparatus. Position stabilization of the beam also occurs here. Two copper pins in the focal plane are used to "straddle" one of the other isobaric beams present. As the separate beams drift, due to variations in magnetic fields or accelerating voltages in the system, a greater amount of current will be deposited on one of the pins than on the other. A proportional correction voltage is applied to the accelerating voltage to realign the stabilization beam symmetrically between the pins, and hence, the desired beam ithin the slot. 
The beam is then directed through a switch magnet which diverts the beam to the desired apparatus. For the experiments in this study, the beam was diverted through $45^{\circ}$ to the beta-ray spectrometer. There is also another electrostatic focusing lens located at the switch magnet for beam height adjustments beyond the separator.

\section{B. Beta-ray spectrometer system}

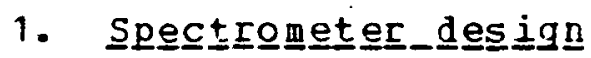

The beta-ray spectrometer is a $\pi \sqrt{2}$ double-focusing type with an average central radius of $30 \mathrm{~cm}$. This design has been described previously in detail elsewhere $(5,10,11)$. The main advantage in the use of a magnetic spectrometer over cther types of electron spectrometers, such as a si(Li) detector, is its better resolution of $0.2 \%$. It is usually operated at a transmission of $0.4 \%$. The improved resolution capability is needed to separate the 93.6-keV L- and 108.8-keV K-conversion lines completely so as to determine the 93.6-keV K/L ratio accurately. This capability is not usually available with a si(Li) detector.

The spectrometer is of the "inside-out" design as shown in figures 2 and 3 . For on-line work, this type is necessary to eliminate effects due to stray magnetic fields and background radiation. By having the electron path enclosed within the magnet coils and iron wall, fringing fields from 


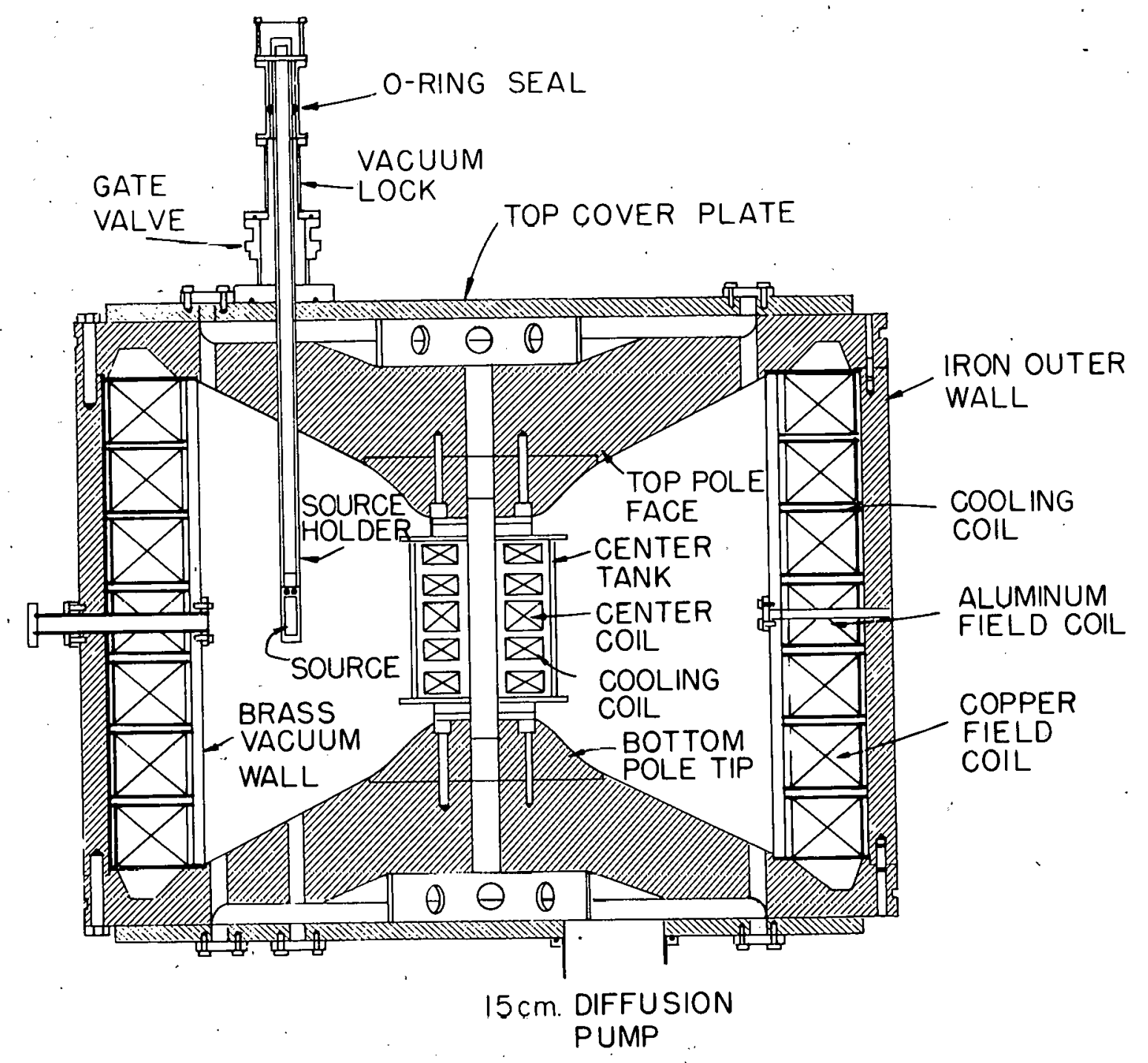

Fiqure 2. cross-section of the TRISTAN beta-ray spectrometer 

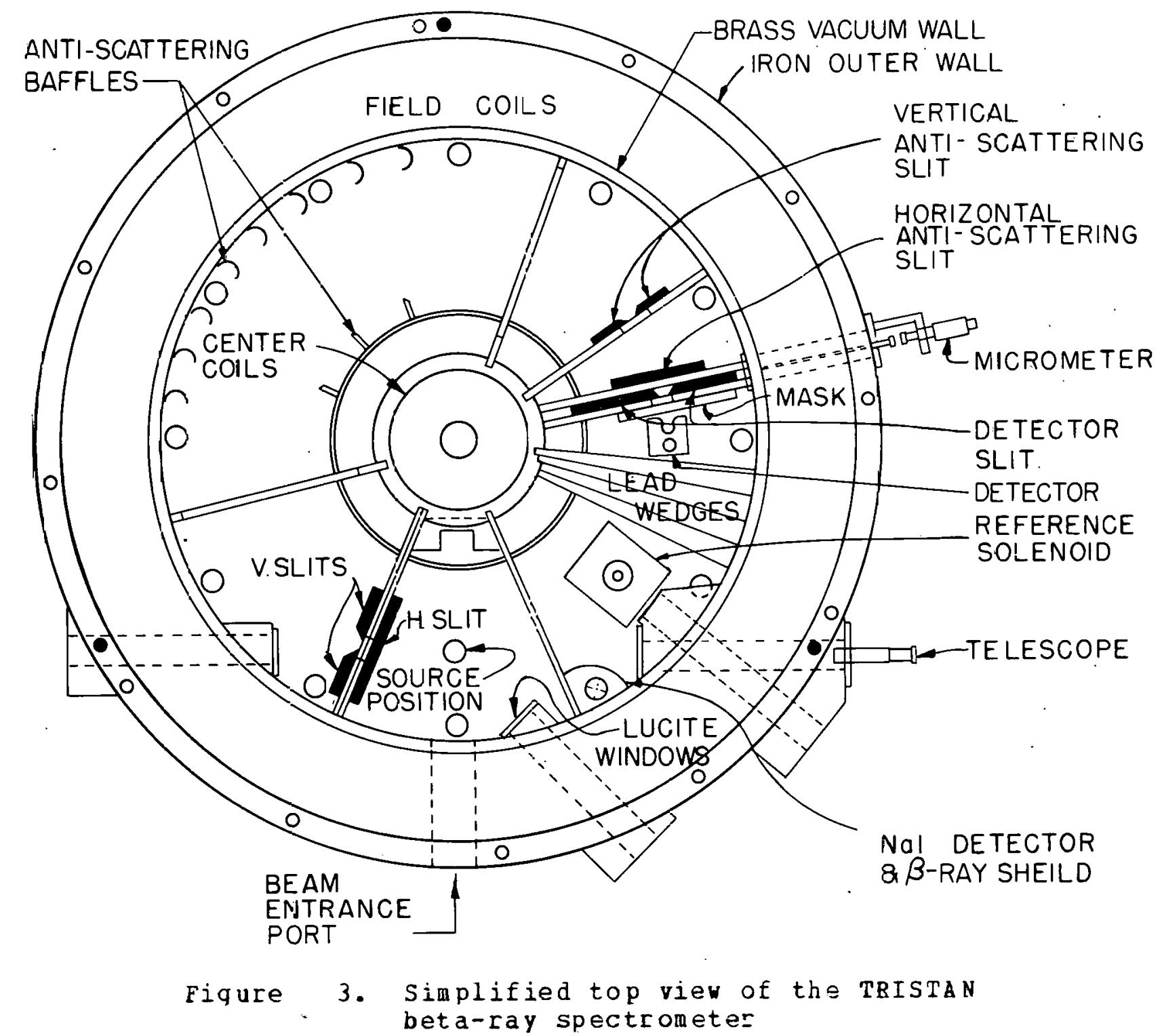
other magnets in the TrIstan system, especially the switch magnet, can be reduced to acceptable levels. Also, this design aids in shielding the detectors from background radiation, part of which arises from the ion beams which are stopped in the collector box.

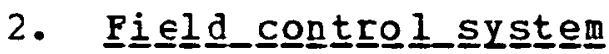

Since a magnetic spectrometer is a single-channel device, that is, during a single counting period, it detects only the electrons emitted within a small momentum interval; it is necessary to employ a field control system to step the spectrometer field through the series of momentum values involved in "scanning" a conversion line or beta spectrum.

The field control system consists of a programable Digital Field selector (PDFS), a reference solenoid, and a field stabilizer. The PDPS, described in detail in refs. 5 and 11, is a hard-wired program which is capable of dividing up the magnetic field range into 500,000 channels. The maximum field corresponds to an energy in excess of 8 Mev. It is possible, with the arailable switch positions, to designate six bands within a spectrum, each having an upper and lower limit, a channel increment, and a data accumulation time. The banding capability allovs one to vary field steps and. count times over different parts of the spectrum. While large steps are sufficient to determine background counts above and below a conversion electron peak, small steps are 
desirable to accurately evaluate the peak area.

Basically, the field control is accomplished as shown in figure 4. The PDFS controls the Fluke voltage calibrator which supplies a voltage proportional to the PDF channel setting to the spectromagnetic current supply for the spectrometer coils, and to the Alpha scientific current supply for the reference solenoid. The solenoid (from ogallala Electronics, ogallala, Nebraska) is a water-cooled, wound aluminum ribbon placed at the 30-cm central radius. Since it is designed to be relatively temperature-independent while its field is directly proportional to the applied current, the solenoid provides a very stable and accurate reference field. The temperature effects on non-linearity of the solenoid are less than $5 \times 10^{-5}$ at maximum field, while the precision limit due to non-linear effects of the momentum calibration are about $2 \times 10^{-5}(5,11)$.

A Hewlett-Packard nuli probe is located at the center of the sclenoid. It senses an inequality between the solenoid and the spectrometer magnetic fields and supplies an error. voltage to the field stabilizer. The field stabilizer then adds a correction voltage to the spectromagnetic power supply for the spectrometer coils. This procedure is necessary since the spectrometer has an lion core. Because of the hysteresis effects of iron, identical coil currents do not always create identical magnetic fields at the electron 


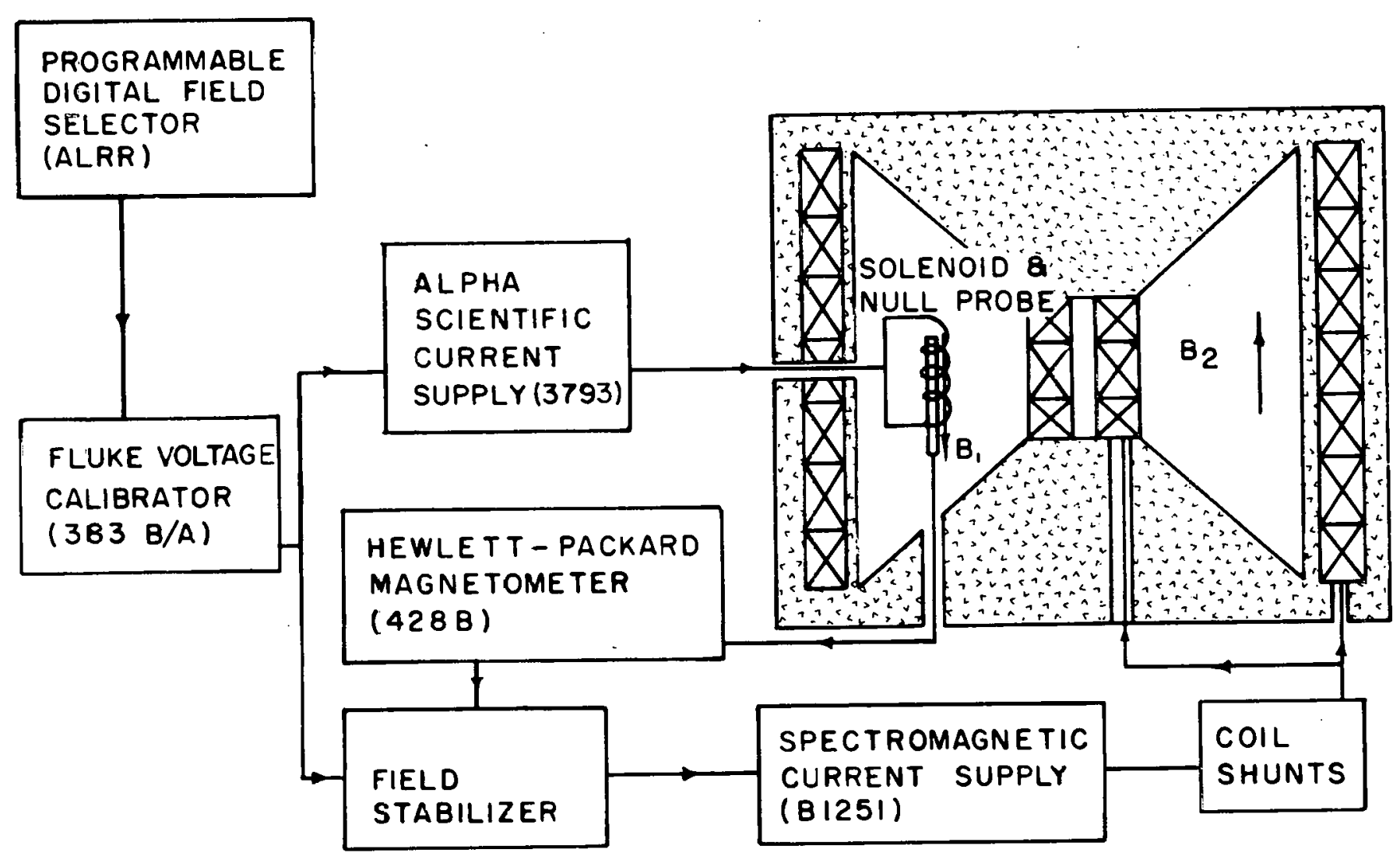

$\vec{v}$

Fiqure 4. Block diagram of magnetic field
control system 
orbit. Also, the presence of iron adds a non-linearity to the relation between the coil current and the magnetic field.

This system has been shown to stabilize very rapidly after large channel increments, and to be very reproducible in focusing over a long period of time (11). The need for a rapid response time is evident when a duty cycle may require many field changes for a short-lived source or the enhancement of a particular source.

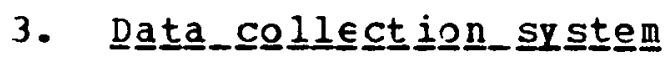

The data collection system associated with the spectroneter consists of nine scaler outputs from four detectors, two timers, and the PDFS as shown in figure 5. At the end of a data collection period, a teletype interface interrogates the scalers and prints out the information on an ASR 33 teletype as well as punching it on paper tape. The PDFS scaler rfarint ronsists of tho channol number.

Electrons in the spectrometer are counted by the beta detector. The beta cietector consists of a dual, gas-flow proportional counter with end-correction electrodes. This dual detector is mounted at the focal point inside the spectrometer and is shielded from source gamma ray by lead wedges. A cut-away view of the detector is shown in figure 6: The foreground detector has a 0.006-mm thick, aluminized Mylar window. The background detector is located directly behind the foreground detector. This windowless detector 


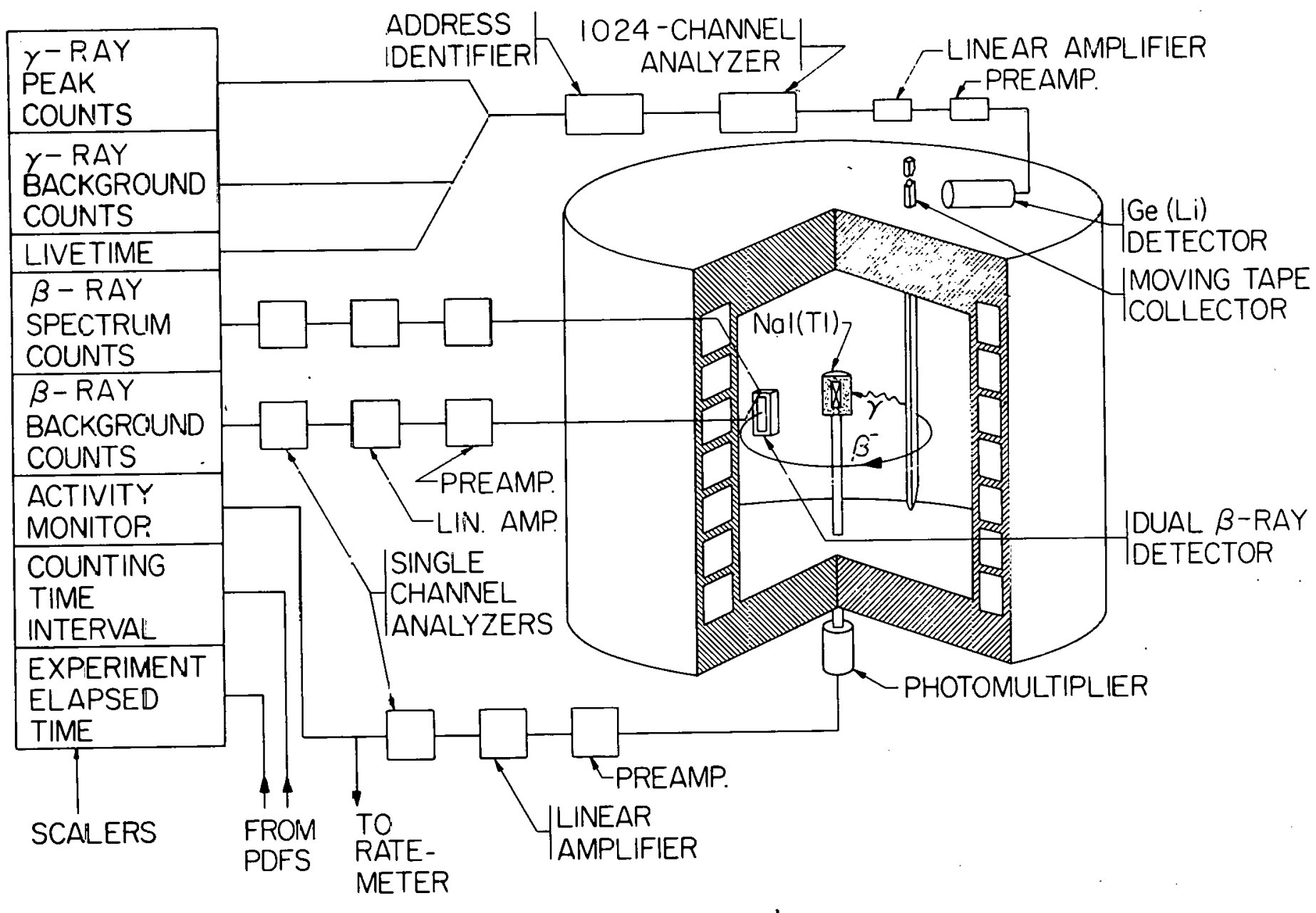

Fiqure 5. Data collection system 


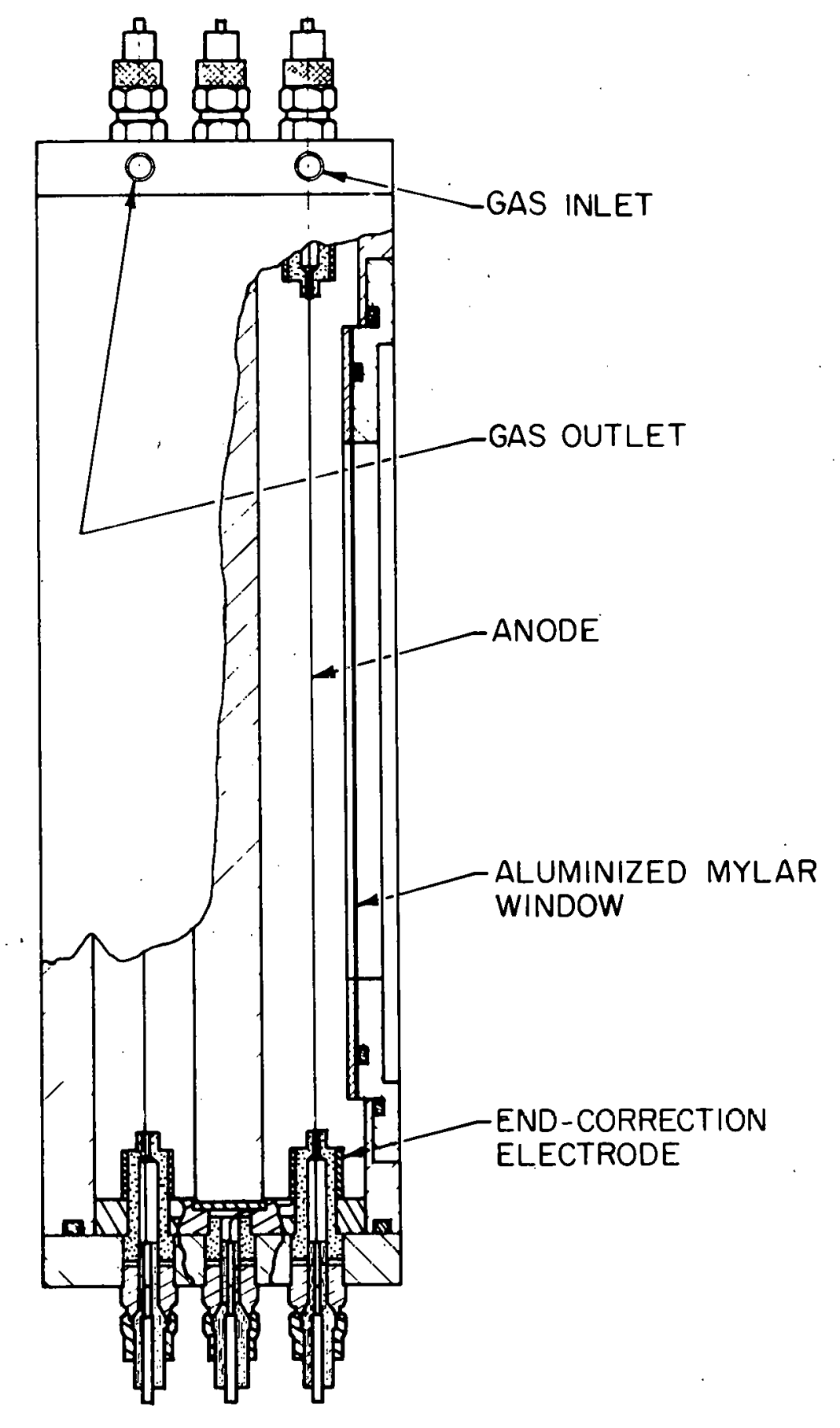

Fiqure 6. Cross-section of the dual detector 
allows simultaneous counting of the background contribution while foreground counting is in progress. It is then possible to correct each data point individually for background counts.

Before the experimental investigations were begun, a series of measurements were made to determine the best operating parameters for the proportional counter. Measurements were made on the energy response of the detector to the current in the spectrometer coils. Another series of measurements vas made to determine the best bias voltage, amplifier gain, and discriminator settings to use. Previously, modifications had been made to the proportional counter consisting of drawing the center electrode to a finer diameter, adding Teflon insulators between voltage connectors and the aluminum housing, and adding a capacitor network to eliminate "crosstalk" signaling between the background and foreground detectors. A $137 \mathrm{Cs}$ source was introduced into the spectrometer to provide electrons for counting purposes.

A series of spectrometer coil currents, $0.3 \mathrm{~A}$ to $1.08 \mathrm{~A}$, vere manually dialed on the spectromagnetic current supply. (1.08 A is the current necessary to detect the $K$-conversion line of $137 \mathrm{Cs}$.$) The detector output was passed through a$ pre-amplifier, amplifier, and discriminator before being introduced into the $1024-c h a n n e l$ analyzer. The resultant data of peak centroid channel number and upper and lower half- 
maximum channel numbers are. plotted against the inversesquare current settings in figure 7. The difference of the upper and lover half-maximum channels is defined to be the Eull width at Half Maximum (FWHM). The inverse square of the channel setting was selected as abscissa since this choice of abscissa linearized the data.

A second series of measurements was made to find the optimum values of the parameters for bias voltage, amplifier gain, and discriminator setting. The method used was to fix two of the parameters and collect counts for a given time at one current setting for various values of the parameter of interest. Then the optimum value of that parameter was held fixed, and another was varied. This was repeated until a combination was found where the count rate was relativoly independent of small variations of the parameters. For example, the amplifier gains and discriminator settings were fixed while measurements were made at 0.3 A for one minute for bias rcltages of $2350 \mathrm{~V}, 2400 \mathrm{~V}$, and $2450 \mathrm{~V}$. Then measur $\leqq m e n t s$ were made at these settings for other currents. As operation at $2450 \mathrm{~V}$ did not introduce an unusually increased count rate, it as used whil $\in$ various discriminator settings were tried until one was noticeably above the "noise" level of the amplifier.

one other problem was investigated. Earlier data had shown displaced and non-reproducible peaks. By utilizing a 


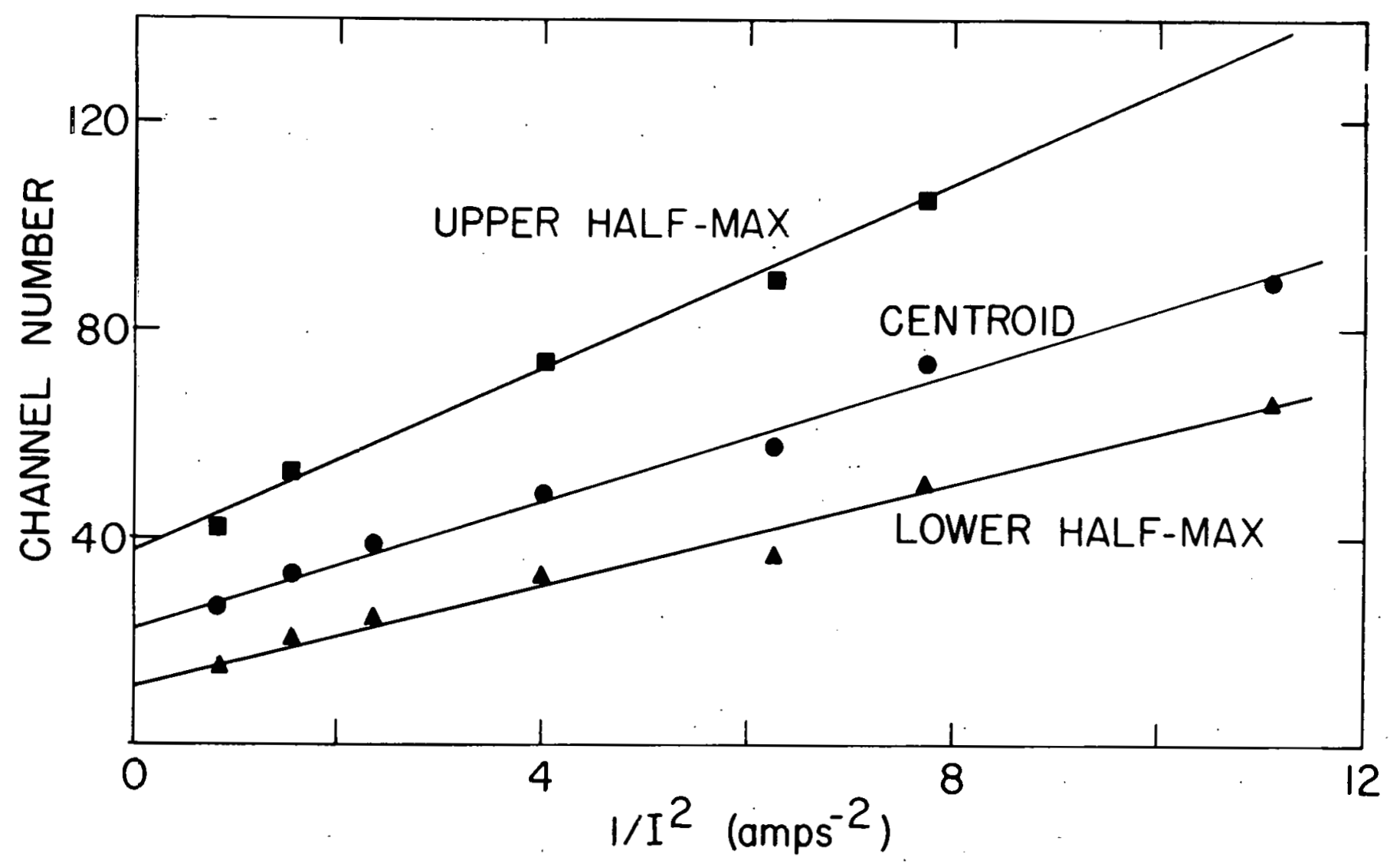

Fiqure 7. Plot of channel numbers for various inverse-square current settings 
needle valve on the gas-flow system situated upstream from the detector and allowing several minutes for the pressure to stabilize before taking data, the reproducibility of the peaks was regained. Apparently, the prior use of a needle valve downstream from the detector was not as effective in stabilizing the gas pressure.

a NaI(TI) crystal is used to monitor activity inside the spectrometer. The crystal is shielded from electrons, allowing a measure of the gamma counting rate. The crystal is connected to an external photomultiplier tube by a 45.7-cm light pipe. This monitor is used mainly to aid in tuning the separator and observing source strength variations during a scan.

In obtaining gamma-ray counts for analysis, a Ge(Li) detector is used with the system. Either a $6-\mathrm{cm}^{3}$ detector is placed on tcp of the spectrometer, or a $60-\mathrm{cm}^{3}$ detector is located at an equatorial port. For this study, a $60-\mathrm{cm}^{3}$ Ge(Ii) detector was located at a median-plane port to allow simultaneous beta-gamma singles measurements to be taken. The Ge(Li) output is routed through a 1024-channel analyzer and an Address Identifier. The Address Identifier allows the digital setting of three windows within the gamma spectrum in the analyzer. The center window provides the gama-ray peak counts which are directed to one scaler. The outer two windows provide gamma-ray background counts to another 
scaler. A timer is used in connection with a gating signal from the analyzer to provide dead-time corrections to the gamma-ray counts. In the data analysis, the gama background counts are subtracted from the peak counts. The background counts are multiplied by a ncrmalization factor if the background window width is unequal to the peak window width. The result is then divided by the count time in minutes corrected for the amount of analyzer 1 ivetime in the counting period. This gives the area of the gama-ray peak only, for the same time interval used to count conversion electrons.

There are two other timers associated with the system. one timer has a crystal-controlled time base and measures the count time. The other timer, knoun as the Time-of-Day, is started at the beginning of the experiment and measures the elapsed time. This is primarily used to provide reference times from which to correct for decay of sources.

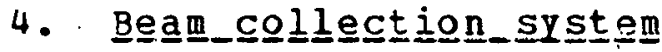

For the purfoses of simplicity, the Moving rape Collector (MTC), the paughter Analysis çontrol (DAC), and the Readout Interface (RI) systems are combined under the beam collection function of the spectrometer system. The RI coordinates the PDFS with the DAC, which controls the MTC. The cac provides timing for the functions of beam collection, delay, data accumulation, and tape movement. The RI also controls the method of data output. Gating signals are sent 
through the PCFS to allow data to be accumulated when the tape is stationary and the DAC has positioned the desired sources. The complete functioning of these systems can be found in refs. 5 and 11 .

The ion beam is deposited on the aluminum side of the aluminized Mylar tape of the MTC. The MTC is a device to allow isobaric separation of the activities provided by the TRISTAN isotope separator. By collecting data at the beam deposition point, the parent activity can be studied. By allowing the ion beam to be deposited on the back side of the MTC probe away from the spectrometer source point, and delaying an amount of time appropriate for the isotope halflife before moving to the accumulation point, the daughter or grandaughter activity can be strongly enhanced in the accumulated data over the parent activity. Since only equilibrium sources were used for this study, the MTC isobaric separation capability was not employed. Therefore, further details of the MTC operation are left to ref. 5. The use of equilibrium sources proved to be sufficient to obtain data as the spectrometer resolution allowed nearly complete separation of the 93.6-kev L-conversion line in the $91 \mathrm{Rb}$ decay from the 108.8-kev. K-conversion line in the $91 \mathrm{KI}$ decay. Since the overlap of the areas of the peaks was not statistically significant, it was not necessary to enhance the individual isotopes in the sources. Therefore, the equilibrium-source 
measurements were easier as no tape movements needed to be made.

For the equilibrium sources used in this study, the DAC was only used to hold the system in the simultaneous collect and accumilate modes to allow beam to be continuously deposited and data to be accumulated for an equilibrium $92 \mathrm{Kr}, 91 \mathrm{Rb}$ source. The $\mathrm{EI}$ was then $h \in l d$ in the mode where the gating signals allowed total control of the data accumulation and readout to be handled by the PDFS. In fact, in one case, the DAC was by-passed with its input signals to the RI obtained ty leaving open or shorting by a terminator plug the appropriate input connectors.

The method of beam stabilization within the spectrometer is noteworthy, however. A stable source position is necessary to maintain spectrometer resolution and calibration. Shifting of the beam position can be caused by variations in the switch magnet field and the spectrometer field. The beam position has been observed tc vary $3 \mathrm{~mm}$ for a 48,000-channel change of the spectrometer field (11). The beam position also shifts in following the stabilization changes in the ccllector bcx. Without stabilization, a 3-mm source shift at channel 48,000 would decrease the resolution from $0.25 \%$ to approximately $0.6 \%$. Stabilization is obviously necessary for high-resclution work. 
The stabilization method is similar to the use of the pins in the collector box but uses the aluminized Mylar tape directly. Use of a pin system rould not work as the pins would act as secondary sources of radioactivity after they became coated by the beam. Therefore, it was decided to use the tape itself by turning it into a two-conductor system. This tape is $12.7 \mathrm{~mm}$ vide by $0.0254 \mathrm{~mm}$ thick. A $0.0089-\mathrm{mm}$ thick layer of aluminum is bonded to one side of the tape. The aluminum layer provides electrical continuity and better retention of the ions. Besides the use of the tape for stabilization, the electrical continuity allows built-up charge to dissipate before the resolution is degraded by the extra acceleration given to the electrons.

A groove, $0.01 \mathrm{~mm}$ deep by $0.3 \mathrm{~mm}$ wide, was ground through the center of the aluminum layer for the length of the tape. The tro aluminized sides are, effectively, electrically isolated conductors wich can act as stabilizer pins. Current from each side of the tape is differentially amplified and directed to a stabilizer which applies a correction voltage to the switch magnet power supply to guide the beam back to the center of the tape, equalizing the current on each side. 
IV. METH OD OF ANALYSIS

A. Introduction

using the definition of an internal conversion coefficient mentioned earlier, the easiest way to determine the ICC of a transition is to measure simultaneously the intensities of the gamma ray and of the internal conversion electrons associatsd with that gama ray. Due to the different binding energies of the atomic orbits, the electron peaks for a given transition will be separated in the spectrometer momentum spectrum. Therefore, peaks may be identified as corresponding to the K-, I-, and M-shells. Measurements, then, will actually yield separate K-, L-, and M-conversion coefficients. A total coefficient can be compounded from these, or the individual coefficients or their ratios may suffice to determine the multipolarity of a transition.

The method of simultaneous beta-gamma singles measurements amcunts to determining the area of the gamm-ray peak as seen in the multi-channel analyzer, and the area of the conversion electron peak as it is scanned by the spectrometer. Ther corrections are made for the efficiency of the Ge(Li) detector, the gama-ray attenuation by the plexiglas window of the spectrometer, and the geometry of the spectrometer. The correction for the geometry of the spectrometer is most easily done by using data taken under identical condi- 
tions for another, well-known transition. The constant geomErry factor of the spectrometer can then be eliminated by using $t b \in$ ratio of the unknown to the known ICC.

This method of simultan cous beta-qamma singles measurements, known as the Normalized conversion peak-to-Gamma peak (NPG) method. Was usza as exhibited in the formula

$$
\alpha_{K}=\alpha_{K^{\prime}} \frac{\left(A e^{/ A} A\right)(\varepsilon)\left(e^{a} x\right)}{\left(A{ }^{\prime / A} \gamma^{\prime}\right)\left(\varepsilon^{\prime}\right) \cdot\left(e^{a x}\right)}
$$

Here, $\alpha_{K^{\prime}}$ is the known ICC, $A_{e}$, and $A_{e}$ are the electron peak areas $\partial \bar{f}$ the known and unknown transitions respectively, 'A $\gamma$ ' and Ay ars the qamma peak areas of the known ard unknown tránsitions respectively, $\varepsilon$ and $\varepsilon^{\prime}$ are the Ge(Ii) detector relative ohotopeak efficiencies at the respective qamma-ray enerqies, and $\epsilon^{\prime} x$ and $\in a x$ are $t h \in$ corrections for qamma-ray abscrfticn losses in the one-half inch plexiglas window of the sp@ctrometar at the qamma-ray enerqies involved. This last cozzetion involved the use of an "average plexiglas mclecula" as $\mathrm{C}_{5} \mathrm{H}_{6}{ }^{\mathrm{O}}$ (12) and tables of gamma-ray attenuation cofficierts (13). The energy-dependent attenuation coefficients are shcwn in Table 1 .

The method cf letermining the gama peak areas was mentioned under the description of the Address Identifier of the 1024-channel analyzer on page 22. The electron peak area is dets[mined as collows: After multiplication by a normal- 
Table 1. Plexiglas attenuation coefficients

\begin{tabular}{|c|c|c|c|c|c|}
\hline $\begin{array}{l}\text { Gamma } \\
\text { Energy } \\
\text { (MeV) }\end{array}$ & $\begin{array}{c}{ }^{2} \mathrm{C}^{1} \\
\left(\mathrm{~cm}^{2} / \mathrm{g}\right)\end{array}$ & $\begin{array}{c}a_{H^{2}} \\
\left(c m^{2} / g\right)\end{array}$ & $\begin{array}{c}{ }^{a_{O}}{ }^{1} \\
\left(c m^{2} / g\right)\end{array}$ & $\begin{array}{c}a_{T^{2}} \\
\left(c m^{2} / g\right)\end{array}$ & ${ }^{a} t^{3}$ \\
\hline $\begin{array}{l}.01 \\
.015 \\
.02 \\
.03 \\
.04 \\
.05 \\
.06 \\
.08 \\
.1 \\
.15 \\
.2 \\
.3 \\
.4 \\
.5 \\
.6 \\
.8 \\
1.0 \\
1.5 \\
2 . \\
3 . \\
4 . \\
5 .\end{array}$ & $\begin{array}{l}2.27 \\
.782 \\
.432 \\
.254 \\
.207 \\
.187 \\
.175 \\
.161 \\
.151 \\
.135 \\
.123 \\
.107 \\
.0953 \\
.0867 \\
.0802 \\
.0707 \\
.0637 \\
.0516 \\
.0443 \\
.0355 \\
.0305 \\
.0271\end{array}$ & $\begin{array}{l}.385 \\
.376 \\
.369 \\
.357 \\
.346 \\
.335 \\
.326 \\
.308 \\
.294 \\
.265 \\
.243 \\
.211 \\
.189 \\
.173 \\
.159 \\
.140 \\
.126 \\
.103 \\
.0872 \\
.0693 \\
.0581 \\
.0505\end{array}$ & $\begin{array}{l}5.72 \\
1.78 \\
.843 \\
.373 \\
.257 \\
.212 \\
.190 \\
.167 \\
.155 \\
.136 \\
.123 \\
.107 \\
.0956 \\
.0873 \\
.0805 \\
.0708 \\
.0636 \\
.0516 \\
.0444 \\
.0359 \\
.0310 \\
.0278\end{array}$ & $\begin{array}{l}3.28 \\
1.08 \\
.062 \\
.300 \\
.232 \\
.204 \\
.189 \\
.172 \\
.161 \\
.143 \\
.130 \\
.113 \\
.101 \\
.0922 \\
.0851 \\
.0750 \\
.0678 \\
.0547 \\
.0469 \\
.0376 \\
.0324 \\
.0288\end{array}$ & $\begin{array}{l}.3 .90 \\
1.29 \\
.669 \\
.357 \\
.276 \\
.243 \\
.225 \\
.205 \\
.192 \\
.170 \\
.155 \\
.134 \\
.120 \\
.110 \\
.101 \\
.0892 \\
.0807 \\
.0651 \\
.0558 \\
.0447 \\
.0386 \\
.0343\end{array}$ \\
\hline
\end{tabular}

1 Attenuation coefficients taken from Storm and Israel (13). $2 \mathrm{~A}$ molecularly-weighted average based on $(12 \mathrm{C})_{5}(1 \mathrm{H})_{6}(16 \mathrm{O})_{2}$. ${ }^{3}$ Based on an average plexiglas density of $1.19 \mathrm{~g} / \mathrm{cm}^{3}$.

ization factor, the electron counts in the background scaler. are subtracted from the foreground counts. These counts are then divided by the count time in minutes and normalized to the source strength which is given by the gama peak area obtained during the same counting time. The resulting electron 
counts are summed numerically over the channel number range that spans the conversion peak. The peak area is then obtained by subtracting the underlying beta continuum as represented by a straight-line fit to the continuum on both sides of the peak.

The relative photopeak efficiencies are determined from a. correction curve that is made for each particular detector. The curve is made by measuring the gama-ray peak areas of many standard sources over a wide energy interval and comparing it to the intensities reported in the literature. At present the determination of the efficiency corrections is believed accurate to $5 \%$.

In determining the error in the ICC, the errors in a 11 factors in the above equation are compounded by standard statistical error propagation. As stated before, the relative photopeak efficiency corrections have a relative error of about $5 \%$, while the error in the gamma-ray absorption correction ratio is about $2 \%$. The relative error in the conversion Iin $=$ areas, which are calculated in the program that determines these areas, is usually less than 1\%. If several scans of the conversion line were obtained, the root-mean-square error was used rather than the generally smaller statistical error in the average conversion line area. 


\section{B. Source Preparation}

For this study three se parate equilibrium sources of mass 91 were collected. In the first tuo cases the sources were collected on the tape from the MTC while it was held stationary. For the last source an external source holder containing a 7-cm length of the "split" tape was used to collect the source. To be certain that the sources were definitely in equilibrium as far as the $91 \mathrm{kr}$ and $91 \mathrm{ab}$ activities were concerned, it was sufficient to delay data accumulation for several minutes after beginning beam deposition on the tape. The half-lives of $91 \mathrm{KI}$ and $91 \mathrm{Rb}$ are about 9 and 60 seconds, respectively (7). The mass 91 isotopes and the levels and transitions involved in this study are shown in figure 8 .

For the first two mass 91 sources, a source of $85 \mathrm{mKr}_{\mathrm{r}}$ was collected subsequent to obtaining the data on mass 91 . This allowed the use of the thoroughly-studied 151-kev transition in $85 \mathrm{Rb}$ to provide a known $K$-conversion coefficient for normalization of the data (14). For the third source collected, the 556-kev transition in $91 \mathrm{my}$ was used as the known, normalization ICC (15). The use of $91 \mathrm{my}$ as the normalization transition in the last source had the advantage that it existed within the same source deposition from which the $91 \mathrm{Kr}$ and $91 \mathrm{Rb}$ data were collected. This eliminated any possibility of 


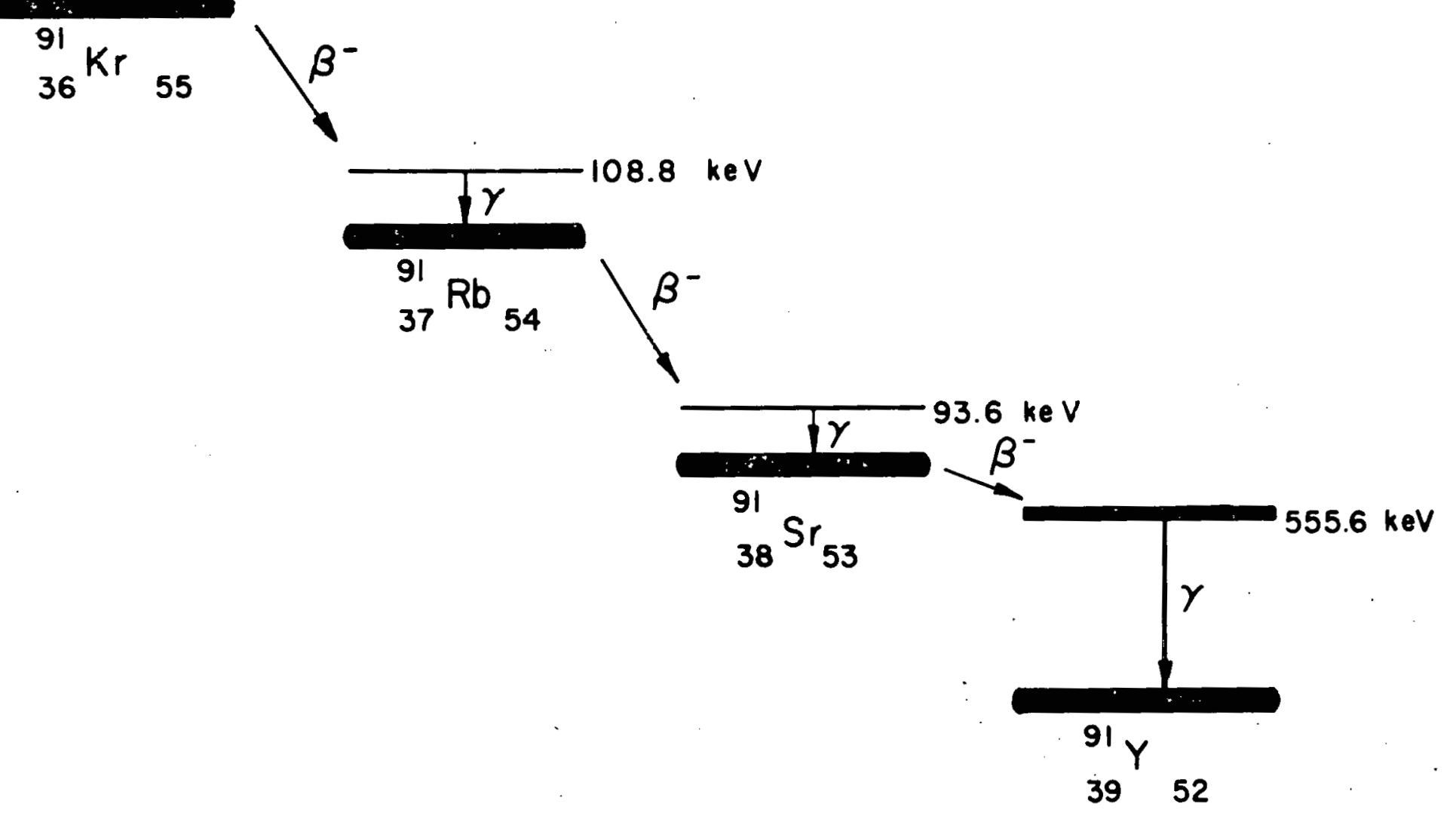

Fiqure 8. Mass 91 isotopes and levels in this study 
the calibration source being depcsited in a slightly different position or with a different shape due to the focus or stabilization, with possible attendant effects on the resolution or transmission of the spectrometer. Such effects, as will be discussed more fully later, can invalidate the assumption that the geometry factor is the same for different depositions.

During the collection of the second source, problems were encountered in electron spectra which were collected. Tho conversion peak shapes persistently exhibited unexpected "shoulders" mid-way up on the high-energy sides of the peaks. Attempts to remove these shoulders by increasing transmission with corresponding loss of resolution failed. The separator was also runing unevenly with unusually large pressure fluctuations. which caused variations of source activity of factors of two. Therefore, data from this source were not used in the results, although a preliminary examination of some of the data gave results not greatly inconsistent with that from the other two sources. The results, which will be discussed below, are shown in Table 2 .

\section{Measurements and Analysis}

From the first source, scans were made of the $93.6-k e v$ $\mathrm{K}$ - and $\mathrm{L}$-conversion lines in $9 \mathrm{IS}$ as well as the $108.8-\mathrm{K} \in \mathrm{V} \mathrm{K}-$ conversion line in $91 \mathrm{Rb}$. The 108.8-keV K-conversion line was not resolved from the weak 93.6-keV M-conversion line as can 


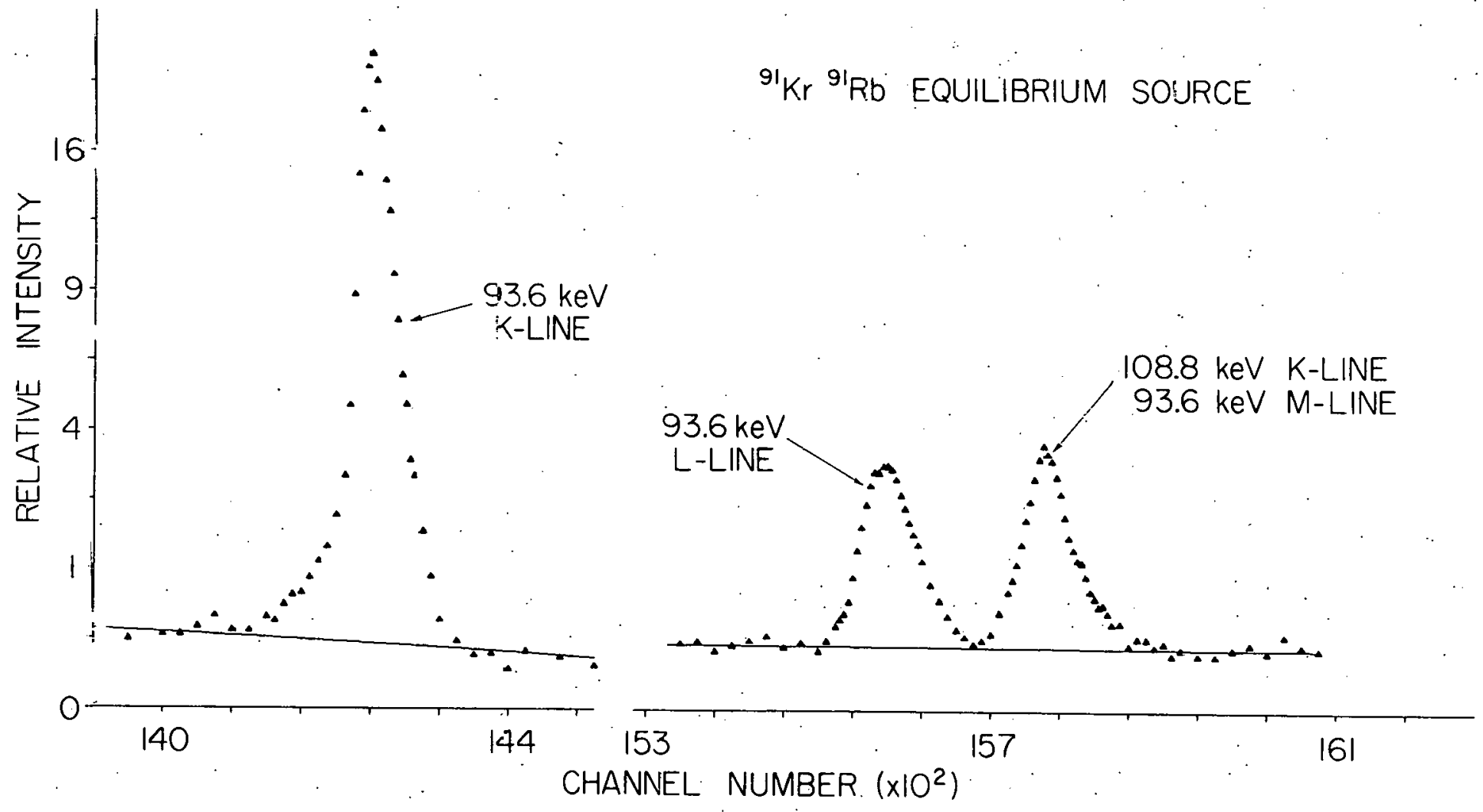

Fiquie 9. Iaternal conversion lines of $93.6-\mathrm{k} e \mathrm{~V}$ and 108.8-keV transitions 
be seen in figure' 9. Since the 93.6-keV L- and 108.8-keV Kconversion lines were resolved, it was possible to determine a K/L ratio for the $93.6-k e V$ transition. The $K / L$ ratio was $5.95 \pm 0.24$, which indicates virtually pure E2 multipolarity since the theoretical E2 value is 5.99. The theoretical $\mathrm{K} / \mathrm{L}$ ratios for E1, M1, M2, and E3 transitions are 9.01, 8.78, 6.83, and 2.65, respectively. Another quantity of interest was the ratio of the $93.6-k e V$-conversion coefficient to the 108.8-keV K-conversion coefficient. This ratio was $10.1 \pm$. 0.48 which is the same as Halbig's ratio of $10.1 \pm 0.54$ (5). The average of these two results, which will be referred to as the $K / K$ ' ratio, is $10.1 \pm 0.36$. This ratio is predominantly the ratio of the $K$-conversion electron intensities. Therefore, this ratio will be independent of any geometry normalization. As will be noted later, the ratio value is very close to the theoretical value for a ratio of an E2, 93.6-keV transition to an M1, 108.8-keV transition. The 93.6-kev K-conversion coefficient from the results of the first source was computed to be $2.665 \pm 0.115$, which indicates a multipolarity of M2 with an E3 mixing of about $7 \%$. In the calculation of the $93.6-k e V$-conversion coefficient, a source of $85 m_{K}$ was used as a normalization source. This coefficient, value was at variarce with the results of the $K / L$ and $K / K^{\prime}$ calculations, wich did not involve any normalization source. 
Table 2. Results of conversion coefficients in the decay. of $91 \mathrm{kr}$

\begin{tabular}{|c|c|c|c|c|c|c|c|c|}
\hline \multirow{2}{*}{$\begin{array}{l}\text { Par } \leqslant n t \\
\text { Nucleus }\end{array}$} & \multirow{2}{*}{$\begin{array}{c}\text { IC } \\
\text { Transi- } \\
\text { tion }\end{array}$} & \multirow{2}{*}{\multicolumn{2}{|c|}{$\begin{array}{l}\text { Ca lc. } \\
\text { ICC }\end{array}$}} & \multicolumn{5}{|c|}{ Theoretical coefficients 1} \\
\hline & & & & E1 & $M 1$ & $\mathrm{E} 2$ & $M 2$ & E 3 \\
\hline $91 \mathrm{Rb}$ & $93.6 \mathrm{~K}$ & \pm & $\begin{array}{l}1.1922 \\
0.063\end{array}$ & 0.109 & 0.172 & 1.09 & 1.85 & 8.89 \\
\hline $91 \mathrm{R} \mathrm{b}$ & $93.6 \mathrm{~L}$ & \pm & $\begin{array}{l}0.2002,3 \\
0.013\end{array}$ & 0.0121 & 0.0196 & 0.182 & 0.27 & 3.36 \\
\hline $91 \mathrm{Rb}$ & $93.6 \mathrm{~K} / \mathrm{L}$ & \pm & $\begin{array}{l}5.953 \\
0.24\end{array}$ & 9.01 & 8.78 & 5.99 & 6.83 & 2.6 \\
\hline $91 \mathrm{Kr}$ & $108.8 \mathrm{~K}$ & \pm & $\begin{array}{l}0.1083 \\
0.007\end{array}$ & 0.0661 & 0.101 & 0.607 & 0.775 & 4.9 \\
\hline
\end{tabular}

1 Theoretical internal conversion coefficients taken from Hager and seltzer (2).

2calculated from data taken from third source.

${ }^{3}$ Calculated from data taken from first source.

The $K / L$ and $K / K$ ' results, wich are internally consistent and invelve no separate normalization source, tend to support the E2 nature of the 93.6-keV transition, as had the earlier studies by Mason and Johns (3), Malmskog and MacDonald (4), and Achterburg et_al. (7). The shell model predicts that a nucleus with three $d_{5 / 2}$ neutrons outside a closed shell of $N=50$ and a closed proton sub-shell of $\mathrm{Z}=$ 38. Will have the lowest excited state as $3 / 2^{+}$. The ground state is $5 / 2^{+}$. This would also imply that the transition to 
the ground state should be E2. Since the $\mathrm{K}$-conversion coefficient calculation was at variance with the other results, and involved an external normalization source, the coefficient calculation was considered unreliable as a characterization of the multipolarity.

Dsing the more reasonable, shell-model assumption of an E2 charactier for the 93.6-kev transition and correcting for an E2 $93.6-k e V$ M-shell contribution to the area of the unresolved 108.8-keV K- and 93.6-keV M-conversion lines, the 93.6-keV K/L ratio allors one to calculate the $108.8-\mathrm{keV} \mathrm{K}-$ conversion coefficient as being $0.108 \pm 0.007$. This agrees well with an almost pure M1 multipolarity. since conversion coefficient measurements involve the ratio of the areas of the conversion electron to gamma-ray peaks for the known and unknown sources, the suspected error could be in the Ge(Li) detector response or the spectrometer and proportional counter system. Measurements were made with both to see if the source of the error could be found and/or minimized. There are four logical possibilities for the source of any systematic errors in determining gamma peak areas. They are: errors in the detector efficiency, scattering within the exit port, variation of response due to magnetic field, or dead-time gating ercors in the analyzer. No variations in the gamma-ray count rate of the Ge(Li) detector had ever been observed for widely separated field settings in 
the spectrometer. Likewise, the small energy interval involved would rule out detector efficiency variations as large as the factors of two to four noted in the conversion coefficient. The Ge(Li) detector relative photopeak efficiency correction change is about $6 \%$ for the energy interval from 93.6 to $151 \mathrm{kev}$. Finally, it did not seem probable that such a factor could arise from scattering of gama rays by the iron walls of the spectrometer as they exit through the port and plexiglas window. Measurements of relative gama intensities taken with sources inside and outside the spectrometer indicated that any possible effects due to scattering by the iron walls were negligible.

To verify the validity of the gamma peak and background counts as they are corrected for deadtime in the analyzer, a $137 \mathrm{Xe}$ beam was introduced in to the spectrometer. Beam collection was then stopped, and the source was allowed to decay. windows vere set about the intense 454-kev, gamma transition in the decay. The peak counts were corrected by subtracting background and dividing the result by the ratio of the gamma livetime to count time. If the livetime correction is accurate, the corrected count rate in counts per minute should follow the decay rate of the source. The results are shown in figure 10. The line represents the source half-life and is displaced for clarity. For deadtimes less than $30 \%$, the results indicated no error in the deadtime 

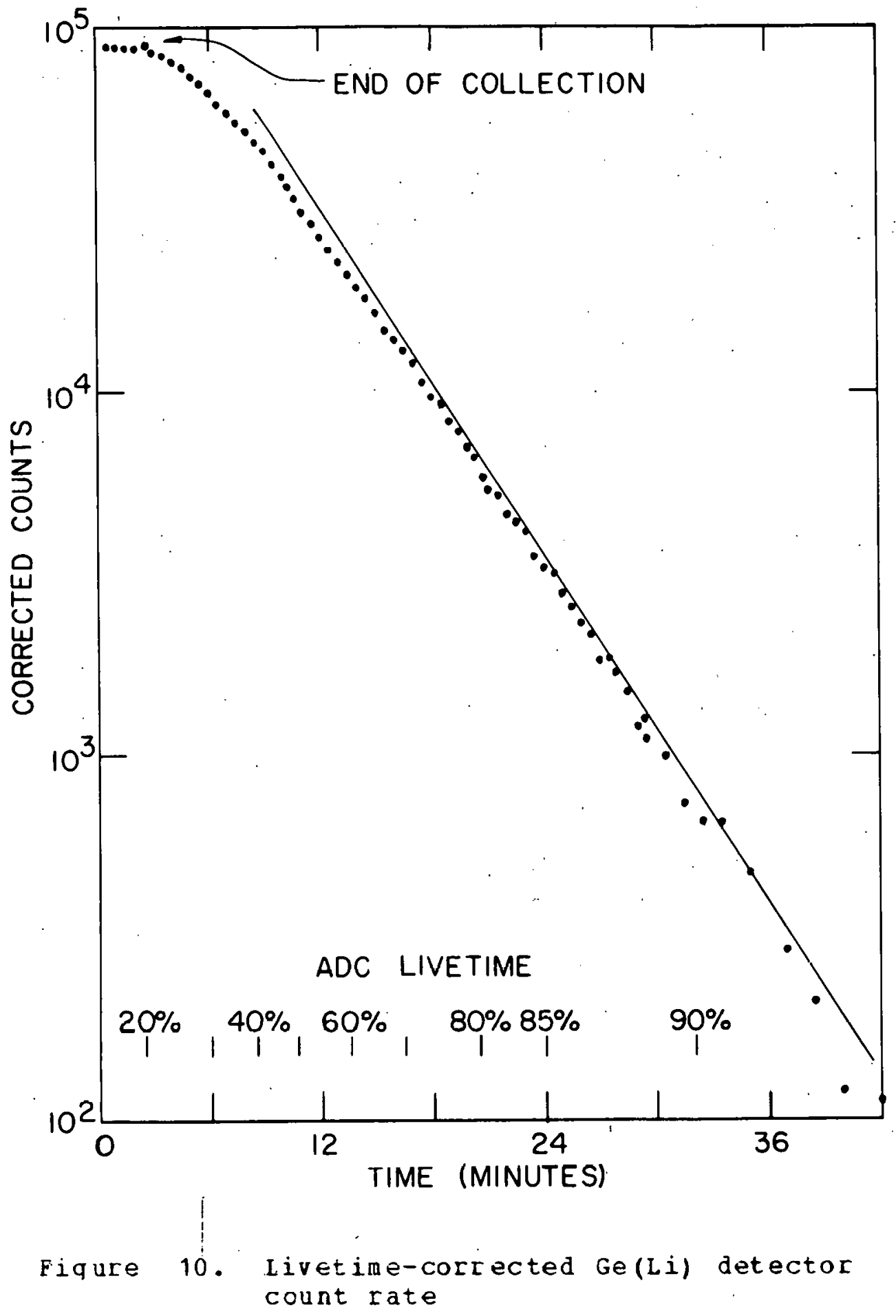
correction procedure. All of the spectrometer measurements made prior to this deadtime correction test had less than $30 \%$ deadtime, thus the error in ICC normalization could not be due to deadtime correction.

Since systematic errors in gamma peak areas were ruled out, it was concluded that the main error must lie with the determination of the conversion electron peak area. Since a proportional counter has virtually $100 \%$ efficiency for all electrons passing through the window, errors in counting must be due to the number of electrons arriving at the counter. And this variation is most probably due to the positioning or shape of the source on the tape within the spectrometer.

To test the effect of the source position on the peak areas, a $137 \mathrm{Cs}$ source in an adjustable holder was placed in the spectrometer. The source position could be varied in steps of $1 / 8$ inch across $a$ widh of $1 / 2$ inch, the vidth of the "split" Mylar tape. Initially, a variation over the tape width produced peak area changes of $5 \%$ to $33 \%$ of the peak area corresponding to the center position. Then the baffles defining the solid angle on the detector side vere maximally opened to see how this would reduce the position dependence. The variations from one side to the other vere $10 \%$ to $9 \%$. Next, the baffles on the source side vere also opened maximally. Ihis gave variations of $15 \%$ to $13 \%$. Finally, with both source and detector baffles wide open, the slit on the 
proportional counter was widened from 0.050 inch to 0.100 inch. This caused variations of $7 \%$ to $6 \%$. Further measurements were taken to adjust the baffles about the openings to provide the most symmetric peaks and uniformity of resolution. The resolutions varied from $0.4 \%$ to $0.6 \%$ across the tape at this final setting. For comparison, the resolution at the center position was about $0.2 \%$ before the baffles were opened wider.

This degradation of the resolution provided peak areas which were relatively insensitive to the change of source position. However, some effect on the areas due to the position of the source remains. The data did not reveal any area effects on the order of a factor of two, which exists between the value of the $93.6-k e v$ K-conversion coefficient and the theoretical value. The reason for the discrepancy thus remains a mystery.

A third source was used to eliminate the inconsistencies in the data on the $93.6-\mathrm{keV}$ transition from the first source. with the sclid-angle adjustments indicated, it was anticipated that the 93.6-keV L- and 108.8-keV $k$-conversion lines would not be resolved. For this reason, the only quantity measured with the third source was the 93.6-keV K-conversion electron peak, as shown in figure 11. The 556-keV M4 transition of $91 \mathrm{my}$ was used to obtain the 93.6-keV K-conversion coefficient. The use of both a larger solid angle and a nor- 


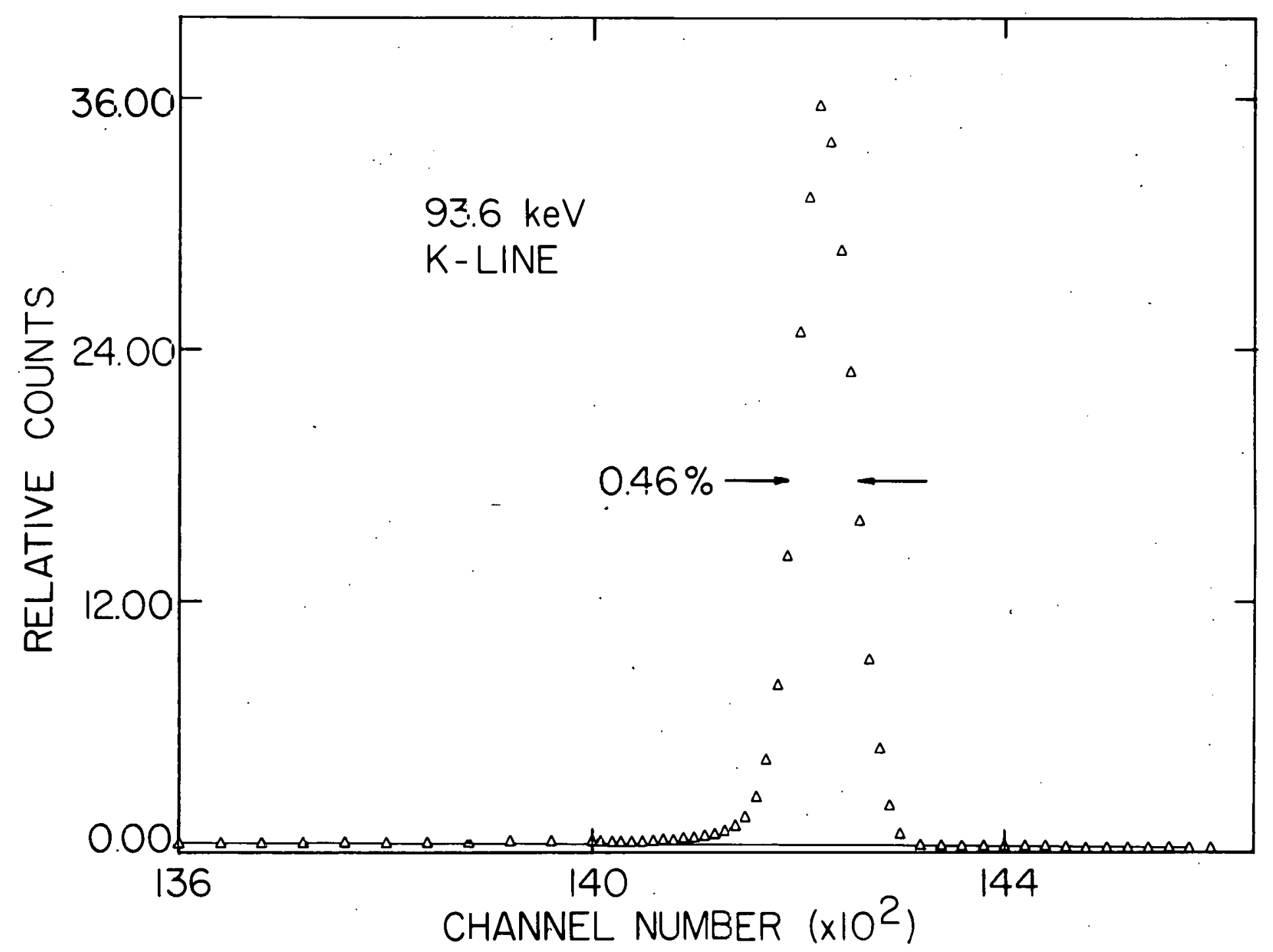

Fiqure 11. 93.6-kev K-convezsion line from third source 
malization transition from the mass 91 deposit were considered to be adequate to eliminate the suspected cause of error in the frevious conversion coefficient measurements.

Three scans of the $93.6-k \in V$ K-conversion 1 ine and four scans of the $556-k e v$-conversion line of $91 \mathrm{~m}_{Y}$ were used in this measurement. A fourth scan of the $93.6-\mathrm{keV}$ line could not be used because the reactor momentarily shut-down during the data collection: The $93.6-k e V$-conversion coefficient was calculated to be $1.192 \pm 0.063$. This is slightly above the theoretical value for a pure E2 transition of 1.09, but it is too far from the M2 value of 1.85 to be that. Concurrently, Glascock (16) has measured the $K-$ conversion coefficients of the $93.6-k e V$ and $108.8-k e v$ transitions by the $\underline{x}-r a y$ Peak-to-gamma peak (XPG) method at the TRISTAN facility. The XPG method involves the simultaneous measurement of $x-r a y$ and gamma-ray intensities. The detector employed for the measurements was a Low Energy photon spectrometer (LEPS). Then the ICC upper limit can be found by dividing the $x$-ray intensity by the gama-ray intensity and fluorescent yield. For these measurements, the TRISTAN gamma-ray MTC was used to provide $92 \mathrm{Kr}$ and $91 \mathrm{Rb}$ sources which were approximately $95 \%$ enhanced. Then the x-ray areas were corrected for intensities due to the isotope that was being discriminated against as well as $90 \mathrm{Kr}$ hydride that was observed, by the use of known fluorescent yields, a known K- 
conversion coefficient for the $121-\mathrm{keV}$ transition in $90 \mathrm{Kr}$, an estimated $K$-conversion coefficient for the non-enhanced $A=$ 91 contominant, and the observed gamma-ray peak areas with relative photopeak efficiency corrections. The two calculations were then reiterated to obtain internal consistency in the estimation of the non-enhanced isotope's $K$-conversion coefficient. This method determined the $k$-conversion coefficients to be $1.012 \pm 0.065$ and $0.108 \pm 0.011$, respectively. for the $93.6-\mathrm{keV}$ and $108.8-\mathrm{keV}$ transitions. These values, as shown in Table 3 , agree with the character of the transitions as being pure E2 for the $93.6-k e V$ and virtually pure M1 for the 108.8-keV transitions.

The XPG IESult of $1.012 \pm 0.065$ for the $93.6 \cdots \mathrm{keV} \mathrm{K}-$ conversion coefficient is in good agreement with the NPG result of $1.192 \pm 0.063$. The weighted average of these two results is 1.105 with a root-mean-square error of 0.088 . It should be emphasized that these two results are completely independent since they involve independent measurement techniques. A further check on the consistency of the results of the $93.6-k e v$ K-conversion coefficients from the NPG and XPG measurements can be made. By multiplying the XPG $\mathrm{K}$-conversion coefficient for the 108.8-keV transition by the spertrometar $\mathrm{k} / \mathrm{k}$ ! ratio, another measure of the $93.6-k e V k-$ conversion coefficient is obtained. This method gives an answer of $1.110 \pm 0.117$, in excellent agreement with the 
Table 3. Internal conversion coefficients and ratios

\begin{tabular}{|c|c|c|c|c|c|}
\hline \multirow{3}{*}{$\begin{array}{c}\text { Internal } \\
\text { Conversion } \\
\text { Transition } \\
93.6 \mathrm{~K}\end{array}$} & \multirow{3}{*}{$\begin{array}{c}\text { Theoret- } \\
\text { ical } \\
\text { value }\end{array}$} & \multicolumn{4}{|c|}{ Calculated values } \\
\hline & & (5) & $\begin{array}{l}\text { Achterburq } \\
\text { et_a } 1 .(7)\end{array}$ & $\begin{array}{c}\text { Gla sc ock } \\
(16)\end{array}$ & $\begin{array}{r}\text { This } \\
\text { study }\end{array}$ \\
\hline & & $\begin{array}{r}4.16 \\
\pm 0.46\end{array}$ & $\begin{array}{r}1.050 \\
\pm 0.100\end{array}$ & $\begin{array}{r}1.012 \\
\pm 0.065\end{array}$ & $\begin{array}{c}1.192^{3} \\
\pm 0.063\end{array}$ \\
\hline $108.8 \mathrm{~K}$ & 0.1014 & $\begin{array}{r}0.412 \\
\pm 0.024\end{array}$ & $\begin{array}{r}0.067 \\
\pm 0.012\end{array}$ & $\begin{array}{r}0.108 \\
\pm 0.011\end{array}$ & $\begin{array}{r}0.1085 \\
\pm 0.007\end{array}$ \\
\hline $9.3 \mathrm{~K} / 108 \mathrm{~K}$ & 10.8 & $\begin{array}{l}10.1 \\
\pm 0.5\end{array}$ & $\begin{array}{r}15.7 \\
\pm 3.2\end{array}$ & $\begin{array}{r}9.4 \\
\pm 1.1\end{array}$ & $\begin{array}{l}10.15 \\
\pm 0.5\end{array}$ \\
\hline
\end{tabular}

1Theoretical internal conversion coefficients taken from. Haqer and Seltzer (2).

2 Assuming pure E2.

${ }^{3}$ Calculated from data taken from third source.

4 Assuminq rure M1.

${ }^{5}$ Calculated from data taken from first source.

above averaqe value.

In addition, the spectrcmetcr $k / K$, ratio may be used with the $1.105 \pm 0.088$ average $k$-conversion coefficient for the 93.6-kev transition from above to obtain another measure. of the 1 c8.8-keV $K$-conversion coefficient. The $K / K^{\prime}$ ratio of 10. 1 divided into the averaqe 93.6-keV k-conversion coefficient of 1.105 qives $0.110 \pm 0.009$ for the $108.8-\mathrm{keV} K-$ conversion coefficient, in excellent agreement with $0.108 \pm$ 
0.011 from the XPG measurement. The averaqe of these two values is $0.109 \pm 0.007$. uhere the error is statistical. 


\section{SUMMARY AND CONCLUSIONS}

The maqnetic beta-ray spectrometer and its associated equipment have been proven a convenient and precise system for the measurenent of internal conversion coefficients associated with nuclear transiticns. This precision is essential tc provide the discrimination necessary in assigning multipolarities to transitions closely-spaced in energy. The reason for the variation in peak areas when using a separate calibration source remains tc be identified, however. Until the variaticn problem is solved, it may be necessary to limit ICC measurements only to transitions ithin a given source ccllection.

In the decay of $91 \mathrm{Kr}$, the $\mathrm{K}$-conversion coefficient of the 108.8-kev transition yas determined to be $0.109 \pm 0.007$. This establishes the transition to be almost pure M1, in contradiction to the El result of Achterburg et_a

In the decay of $91 \mathrm{Rb}$, the $\mathrm{K}$-conversion coefficient of the 93.6-kev transition was deduced to be $1.10 \pm 0.09$. Furthermore. the $\mathrm{K} / \mathrm{L} \cdot \mathrm{ratio}$ as determined to be $5.95 \pm 0.24$. Toqether, these results estaklish the transition to be pure E2. in contradiction to the results of Halbig (5). It is believed that about $50 \%$ of the error in Halbig's result may be due to the use of the wrong relative photopeak efficiency correcticn for the $G \in(L i)$ detector employed. presumably, the 
remaining error was due to the beam focus or source positioning $c n$ the tape, as noted in this study.

The ICC results obtained in this study imply that there are no parity-chanqing transitions between the ground and first excited states of either $91 \mathrm{Rb}$ or $91 \mathrm{Sr}$. As mentioned previously, the qround state of $91 \mathrm{Rb}$ should be predominantly a $\mathrm{f}_{5 / 2}$ proton hole. The first opposite parity state would consist of a $a_{9 / 2}$ particle at relatively high enerqy, approximately 2 Mev. These considerations led Achterburg et_al (7) to ccnsider a stable deformation to explain the existence of a parity-chanqing transition between the lowest excitedstate and the qround state, although $91 \mathrm{Rb}$ is only one proton from a closed sut-shell of 38 and just four neutrons past a closed shell cf 50, hardly a nucleus for which low-energy stable deformations would be expected. The results of the present studr require no such unlikely assumption. In the case of $91 \mathrm{sr}$. Halbig (5) has noted that the qround state of $5 / 2^{+}$is explained by the closed proton subshell and three $d_{5 / 2}$ neutrons. Again no parity-changing transitions would be expected at such a low-enerqy level. It may be noted that Talmi and Unna (17) have shown that M1 transitions amonq identical particle configurations are strongly hindered. This is a further argument for a pure E2 transition. They also have shown that the lowest levels should be $3 / 2^{+}$, and $9 / 2^{+}$at a hiqher energy. 
The results of this study eliminate the need for any Elaborate and unusual explanations which modify the accepted shell model that has been observed to work very vell in the reqion near closed particle sub-shells. 


\section{LIT ERATURE CITED}

1. S. A. Moszkowski. "Theory of multipole radiation" in

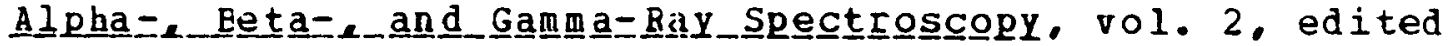
ky K. Sieqkahn (North-Holland, Amsterdam, 1965), p. 864 .

2. R. S. Haqer and E. C. Seltzer, "Internal conversion tables, part I: K-. L-. M-shell conversion coefficients for $\mathrm{Z}=30$ to $\mathrm{Z}=103^{\prime \prime}$. Nucl. Data A4. 41 (1968).

3. J. F. Mason and M. W. Johns, "Level structures of $91 \mathrm{ab}$ and $91 \mathrm{Sr}$ as populated in reta decay". Can. J. Phys. 4 . $2895(1970)$.

4. S. G. Malmskoq and J. MacDonald. "The $93.54 \mathrm{kev}$ level in 91SI", Nucl. Phys. A1142, 263 (1970).

5. J. K. Halbiq. "The beta decay of gaseous fission products". Ph.D. thesis, Iowa State University, 1973 (unpub1ished).

6. D. P. Ames, I. E. Bunker, L. M. Langer, and B. M. Sorenson. "The disintegration of Sr9l and Y91mu. Phys. Fev. 91, 68 (1953).

7. E. Achterburq. F. C. Iqlesias, A. E. Jech, J.A. Moraques, D. Otero, M. L. Perez, A. N. Proto, J. W. Rossi, and $W$. Scheuer. "Levels of $91 \mathrm{Rb}$ and $91 \mathrm{sr}$ fed in the decays of $91 \mathrm{KI}$ and $91 \mathrm{Rb}^{\prime \prime}$. Phys. Fev. C‥ 299 (1974).

8. . L. Talbert, Jr. and D. Thomas, "Design considerations for a system to investigate short-lived nuclei produced at a reactor". Nucl. Instrum. Methods 38, 306 (1965).

9. W. L. Talbert, Jr, and J. R. McConnell, "preparation for on-line studies of short-lived nuclei produced by a reactor". Ark. Fys. 고. 99 (1967).

10. A. A. Bartlett, R. A. Ristinen, and R. P. Bird, "A new double focusing beta spectrometer and the empirical optimization of its performance". Nucl. Instrum. Methods 17. $188(1962)$.

11. J. K. Halbiq. F. K. Hohn, and H. L. Talbert, Jr.. "A magnetic spectrometer system for on-line studies of beta-rays and internal conversion electrons of short-lived activities". Kev. Sci. Instrum. 45. 789 (1974). 
12. J. F. Mriqht, private communication. 1974.

13. E. Storm and H. I. Isra $\in 1$, "Photon cross sections from 1 kev to.100 Mev for elements $z=1$ to $z=100^{\prime \prime}$. Nucl. Data A I. 565 (1970).

14. F. K. Wohn, W. L. Talbert, Jr., and J. K. Halbig, "The decay of esmkr". Nucl. Phys. $\underline{A} 1 \underline{5} \underline{2}, 561$ (1970).

15. J. K. Halbiq. F. K. Hohn, H. L. Talbert, Jr., J. J. Eitter, and J.R. McConne11. "The beta decay of $91 \mathrm{Sr}$, Nucl. Phrs. A2 20⒊ 532 (1973).

16. M. D. Glascock, private communication. 1974.

17. I. Talmi and I. Unna, "Theoretical interpretation of enerqy levels in liqht nuclei". Ann. Bev. of Nucl. Sci. 10. $353(1960)$. 


\section{AC KNOWLEDGMENTS}

This author wishes to express his deep appreciation to the many people who have provided assistance and encouraqement during this study:

Dr. Fred K. Wohn, who served as thesis advisor and quided this project to completion. He has assisted immeasurably by sugqesting the subject of this study and providing interpretations of the results. His patience and steadfastness with this ty ro will be long appreciated.

Dr. Willard L. Talbert, Jr., who quided me into nuclear physics and was responsible for the TRISTAN system which made this study possible.

John R. Mcconnell, who was the real "hands" and "heart" of TRISTAN.

Dr. W. C. Schick, Mike Glascock, and the rest of the members of Group VII for their support.

D. Lekwa, H. Skank, J. Homer, and G. Sleege, who have kept the spectrometer system operating so experiments could be done.

My wife, susan, who has persevered above and beyond the call of duty. 